\title{
We should not forget the foot: relations between signs and symptoms, damage, and function in rheumatoid arthritis
}

\author{
Henriëtte Baan • Wiepke Drossaers-Bakker • \\ Rosemary Dubbeldam • Mart van de Laar
}

Received: 5 January 2011 /Revised: 10 May 2011 / Accepted: 11 May 2011 / Published online: 26 May 2011

(C) The Author(s) 2011. This article is published with open access at Springerlink.com

\begin{abstract}
We studied rheumatoid arthritis (RA) patients with foot complaints to address the associations between clinical signs and symptoms, radiographic changes, and function in connection with disease duration. Secondly, we describe the contribution of several foot segments to the clinical presentation and function. In $30 \mathrm{RA}$ patients with complaints of their feet, attributed to either signs of arthritis and/or radiographic damage, we compared radiographic, ultrasound, clinical, and functional parameters of the feet and ankle. Pain and swelling of the ankle were correlated weakly but statistically significantly with limitation and disability (0.273 to 0.293$)$ as measured on the 5-Foot Function Index (FFI). The clinical signs of the forefoot joints did not influence any of the functional outcome measures. Radiographic scores for both forefeet $(\mathrm{SvdH})$ and hindfeet (Larsen) were correlated with the total Health Assessment Questionnaire Disability Index (HAQ DI) and the 5-FFI limitation subscale. Pain and disease duration, more than radiographic damage, influence the total HAQ
\end{abstract}

\section{H. Baan}

Ziekenhuis Groep Twente,

Almelo \& Hengelo, The Netherlands

H. Baan · W. Drossaers-Bakker · M. van de Laar

Arthritis Centre Twente, University Twente \& Medisch Spectrum

Twente,

Enschede, The Netherlands

R. Dubbeldam

Roessingh Research and Development,

Enschede, The Netherlands

H. Baan $(\bowtie)$

Department of Rheumatology, ZGT,

Locatie Twenteborg Ziekenhuis, Postbus 7600, 7600 SZ Almelo,

The Netherlands

e-mail: h.baan@a1.nl
DI significantly. With the progression of time, structural damage and function of the rheumatic foot worsen in RA patients. Pain and swelling of the ankle contribute more to disability than radiographic damage of the foot and ankle.

Keywords Ankle · 5-FFI · Foot · Function · HAQ · Radiographic damage $\cdot$ Rheumatoid arthritis

\section{Introduction}

In rheumatic conditions, especially rheumatoid arthritis (RA), signs and symptoms of the feet are common. The majority of RA patients present with arthritis of the feet and $20 \%$ of them have radiographic damage at the time of diagnosis [1]. In RA, both forefoot and hindfoot involvement is associated with disease duration and lead to severe impairment and disability $[2,3]$. After 6 years of disease duration, up to $50 \%$ of the patients have considerable radiographic damage in the ankle and the tarsus [4]. Despite the extent of the problem, the rheumatoid foot is neglected. Although in the last few years some scientific interest has arisen, there is still limited interest in the foot in RA in the clinic possibly causing under treatment [1]. In this study, we examined patients suffering from RA and common foot complaints to investigate the associations between clinical signs and symptoms, structural damage, and function in connection with disease duration. Secondly, we explored the contribution of several foot segments to the clinical presentation and function.

\section{Patients and methods}

We performed a cross-sectional observational study. Thirty consecutive RA patients of the outpatient clinic of the 
Arthritis Centre Twente were recruited. To be included, patients had signs or symptoms of arthritis and/or radiographic damage of the feet or ankles due to RA. They had to meet the 1987 ACR criteria for RA. The local ethical committee approved this study and a written informed consent was obtained from each patient.

The following demographic and clinical variables were collected: age, sex, disease duration, total number of used DMARDS, rheumatoid factor DAS 28 [5], and painful or swollen joints in the foot.

All patients underwent ultrasound investigation of the feet and ankles to measure synovitis (0 to 3 ), effusion (0 to 3 ), and power Doppler (PDUS) signals ( 0 to 3 ) according to the method described by Szkudlarek [6]. The following joints were examined: the tibiotalar joint, the subtalar joint, the talonavicular joint, and the five metatarsophalangeals (MTPs). An experienced rheumatologist, who had undertaken specific postgraduate training in ultrasonography, performed the ultrasound investigation on a Logic 9 (GE) with a 9-13 MHz linear probe. To simplify the analysis, a total PDUS score was calculated for the MTPs as well as for the hindfoot joints by adding up the PDUS of the individual joints. This was also done for total synovitis, total effusion, and total erosion score.

To assess radiological structural damage, two experienced readers (WD, HB) read the radiographs of the feet. According to the method, Sharp/van der Heijde, each side of the MTP or IP joint was scored for erosions from 0 to 5 with a maximum of 10 for both sides of the joint, and for joint space narrowing from 0 to 4 with a maximum of 4 per joint. For the total Sharp/van der Heijde score, the erosions and joint space narrowing scores were added. The maximum total score for both feet adds up to 168 [7].

In addition, we read the tibiotalar joint, the subtalar joint, and the talonavicular joint following the Larsen method, in which erosions and joint space narrowing as well as other signs of inflammation are expressed in one score with a range from 0 (normal) to 5 (total mutilation of the joint). The scoring is based on the comparison with the standard film series as described by Larsen [8].

In each patient, we measured the Joint Alignment and Motion (JAM) scale of feet and ankle according to the description of Spiegel et al. [9]. It consists of a five-point scale for each joint. A score of 0 represents a normal range of motion (ROM) and alignment, a score of 1 , a $0 \%$ to $5 \%$ decrease in ROM or malalignment, a score of 2 , a $6 \%$ to $25 \%$ decrease in ROM or mild malalignment, a score of 3 , a $26 \%$ to $75 \%$ decrease in ROM or joint subluxation, and a score of 4 , a $76 \%$ to $100 \%$ decrease in ROM or joint fusion or joint dislocation. The JAM score for an individual joint represents the most severe or limiting aspect of either motion or alignment.
Function was measured by the following variables: Health Assessment Questionnaire (HAQ), Arthritis Impact Measurement Scales (AIMS), and 5-Foot Function Index (5-FFI). The HAQ has been developed by Fries et al. and was adapted for the Dutch population [10]. The questionnaire consists of eight categories, which represent the activities of daily living, and for each category, there are two to four questions. The responses are scored on a fourpoint scale: 0 without difficulty; 1 with some difficulty; 2 with difficulty; and 3 impossible. The questionnaire has a final column in which respondents can indicate the use of any aid or device. The use of any of these devices is scored by at least a 2 . The highest score for each of the eight categories is taken as the score for that category. The final score of the questionnaire is the averaged score of all the categories and ranges between 0 and 3 .

The AIMS score is a widely used instrument and has been adapted and validated for the Dutch language and culture [11]. The score consists of 77 items divided into 12 scales. These 12 scales can be combined into five components: physical health, psychological health, symptoms, social interaction, and work. The scales vary from 0 (good health) to 10 (bad health). The components for psychological health and social interaction and work were used to describe psychosocial functioning.

The 5-FFI is a self-administered index consisting of 23 items divided into three scales (Limitation, Pain, and Disability). We used the validated five-point Dutch language version [12]. The items of the FFI-5pt are identical to those of the FFI but are rated on a five-point visual rating scale ranging from "never" (0) to "always" [4] on the Limitation scale, "no pain" (0) to "intense pain" [4] on the Pain scale, and "no difficulty" (0) to "impossible" [4] on the Disability scale. To calculate the definitive scale scores, the item scores are summed, divided by the maximum possible sum of the item scores, and then multiplied by 100. The total score is the mean of the three scale scores [12].

Statistical analysis The association between the signs, symptoms, damage, and function parameters were calculated using Spearman's correlation. Afterwards, we performed regression analysis in order to assess the most important variables that predict the functional outcome (HAQ) in our model. For the data analysis, we used the Statistical Package for the Social Sciences (SPSS 16.0).

\section{Results}

Thirty patients were included, of whom 25 were female. The mean age was 54 years, and median disease duration was 8 years. Twenty had a positive rheumatoid factor. The 
median HAQ DI was 1.18, and Larsen and Sharp/van der Heijde scores were 1.0 and 4.0, respectively.

Table 1 presents Spearman's correlation coefficients of the correlation between clinical signs and function. Clinical signs were the presence of either swelling or pain as a sign of joint inflammation. Pain and swelling of the ankle showed weak but statistically significant correlation coefficients between 0.273 and 0.293 with limitation and disability, measured on the 5-FFI, as well as with the HAQ and the mobility subscale of the AIMS. The clinical signs of the forefoot joints did not correlate with any of the functional outcome measures. Of the ultrasound (US) parameters, only PDUS of the hindfoot showed a weak but statistically significant correlation with the HAQ walking.

In Table 2, we present the Spearman's correlation coefficients between structural damage and function. Both the Larsen and the Sharp/van der Heijde showed a statistically significant correlation $\left(r_{\mathrm{s}}=0.263\right.$ and 0.277 , respectively) with the total HAQ DI. Further, the Larsen score correlated with the 5-FFI limitation subscale $\left(r_{\mathrm{s}}=\right.$ 0.282 ). There was a moderate negative correlation between the JAM and 5-FFI pain $\left(r_{\mathrm{s}}=-0.325\right)$. The JAM did not correlate significantly with any of the other functional measures. Swelling of the MTPs showed a negative correlation $\left(r_{\mathrm{s}}=-0.516\right)$ with disease duration. All measures of structural damage as well as the total HAQ DI correlated moderate with disease duration: JAM $\left(r_{\mathrm{s}}=-0.584\right)$, SvdH $\left(r_{\mathrm{s}}=0.660\right)$, (Larsen $\left.r_{\mathrm{s}}=0.470\right)$, and HAQ DI $\left(r_{\mathrm{s}}=0.470\right)$. None of the 5FFI subscales correlated with disease duration.

\section{Regression model}

We searched for the variables explaining the variance in the total HAQ DI. The following variables were entered: disease duration, 5-FFI total pain score, swelling ankle, US synovitis total score, and the $\mathrm{SvdH}$ score. These variables were entered on basis of their correlation coefficient $(>0.3)$ or they were judged as important predictors of the HAQ in earlier studies [13]. Using the enter method, a significant model emerged $(F=21.316, p<$ $0.001)$. Sixty-four percent of the variance in HAQ DI score is explained by the following variables: disease duration, 5FFI pain subscale, and swelling of the ankle. The regression coefficients with the $95 \%$ CI are presented in Table 3.

\section{Discussion}

In this study, we explored associations between clinical signs and symptoms, structural damage, and function in connection with disease duration and the contribution of the individual foot segments.

Our data suggest that impaired foot function is associated more with signs and symptoms of the ankle than with forefoot complaints. Function of the foot is only weakly associated with overall radiological damage but again with a larger impact of the hindfoot. Finally, disease duration influences damage and function as well.

When regarding clinical signs in relation to function, we found that the results of our observational cross-sectional study are partially in line with earlier studies. In our study, pain and swelling of the ankle correlated weakly but statistically significantly with function, whereas forefoot symptoms did not. These findings confirm earlier studies suggesting that subjective pain of the forefoot does not correlate with function [14] and that patients considered their ankle complaints more impactful than forefoot complaints [1]. The ultimate function of the feet, walking, is severely and more impaired by rear foot disease than by forefoot involvement [15].

Regarding the relation between radiological damage and function, we found that both the Larsen and the Sharp/van der Heijde score correlated weakly with the HAQ DI but fell out of the regression model. The Larsen score correlated with the 5-FFI-limitation subscale, this is in line with preceding studies, which showed that general joint damage is correlated with loss of function [4, 13, 16]. Furthermore, there was a weak correlation between the

Table 1 Spearman's correlations coefficients ( $p$ value) between clinical signs/symptoms and function

\begin{tabular}{lllllll}
\hline & Pain ankle & Swelling ankle & Pain MTPs/toes & Swelling MTPs & US PD MTPs & US PD hind foot \\
\hline 5-FFI limitation & $0.273(0.034)$ & $0.290(0.025)$ & $-0.200(0.126)$ & $-0.166(0.206)$ & $-0.045(0.734)$ & $0.127(0.334)$ \\
5-FFI pain & $0.095(0.470)$ & $0.010(0.940)$ & $-0.049(0.710)$ & $-0.027(0.836)$ & $0.176(0.178)$ & $0.025(0.851)$ \\
5-FFI disability & $0.293(0.023)$ & $0.278(0.032)$ & $-0.248(0.056)$ & $-0.168(0.200)$ & $0.019(0.885)$ & $0.023(0.860)$ \\
HAQ walking & $0.098(0.455)$ & $0.104(0.428)$ & $-0.234(0.071)$ & $-0.189(0.147)$ & $0.167(0.203)$ & $0.374(0.003)$ \\
Total HAQ & $0.053(0.689)$ & $0.353(0.006)$ & $-0.133(0.309)$ & $-0.073(0.579)$ & $0.169(0.196)$ & $0.112(0.396)$ \\
AIMS mobility level & $0.257(0.047)$ & $0.286(0.027)$ & $-0.02(0.882)$ & $-0.029(0.824)$ & $0.005(0.967)$ & $0.142(0.280)$ \\
\hline
\end{tabular}

5-FFI Five Foot Function Index, HAQ Health Assessment Questionnaire, AIMS Arthritis Impact Measurement Scales, US PD ultrasound power Doppler, MTPs metatarsophalangeals 
Table 2 Spearman's correlations coefficients ( $p$ value) between radiographic damage/limitation and function

\begin{tabular}{|c|c|c|c|c|c|}
\hline & $\mathrm{SvdH}$ & Larsen & JAM feet & US er HF & US er FF \\
\hline 5-FFI limitation & $0.190(0.154)$ & $0.282(0.032)$ & $0.163(0.212)$ & $0.135(0.303)$ & $0.263(0.046)$ \\
\hline 5-FFI pain & $-0.054(0.689)$ & $0.051(0.702)$ & $-0.325(0.011)$ & $-0.149(0.255)$ & $-0.164(0.210)$ \\
\hline 5-FFI disability & $0.002(0.991)$ & $0.195(0.142)$ & $-0.080(0.541)$ & $0.106(0.422)$ & $-0.033(0.801)$ \\
\hline HAQ walking & $0.001(0.993)$ & $0.242(0.067)$ & $0.047(0.724)$ & $0.137(0.295)$ & $0.177(0.175)$ \\
\hline Total HAQ & $0.277(0.035)$ & $0.263(0.046)$ & $0.194(0.138)$ & $0.073(0.582)$ & $0.165(0.208)$ \\
\hline AIMS mobility level & $0.134(0.314)$ & $0.162(0.226)$ & $-0.06(0.648)$ & $0.072(0.587)$ & $0.173(0.187)$ \\
\hline
\end{tabular}

5-FFI Five Foot Function Index, HAQ Health Assessment Questionnaire, AIMS Arthritis Impact Measurement Scales, SvdH Sharp/van der Heijde, JAM Joint Alignment Motion Scale, US er HF Ultrasound Erosion Score Hindfeet, US er FF ultrasound erosion score forefeet

Larsen score (ankle, talonavicular, and subtalar joint) and the 5-FFI-limitation subscale, which may reflect the seriousness of destruction of the hindfoot and ankle.

With disease duration, function (HAQ) also worsened. The triangle of increasing radiological damage, worsening function with longer disease duration has been described by many others, varying from stable progression rate [17] to a steeper worsening, but earlier plateau [18]. Belt et al. concluded that after 20 years of follow-up, the subtalar joint and ankle were affected in 24 of the 103 patients but leading to severe impairment [19]. The JAM, presented as a measure of joint deformity, also correlates with disease duration in our rather established RA cohort. In an early RA population, one might imagine that the JAM predominantly reflects disease activity and would not show a relationship with disease duration. Swelling of the MTPs correlated negatively with disease duration. This might reflect the treatment effect and among others is shown in the study of Welsing et al. [20].

In the regression analysis, we found that disease duration, pain, and swelling of the ankle were the only significant predictors of the HAQ DI. This is in line with other studies, which report pain as one of the most important predictors of the HAQ DI followed by disease activity and radiographic damage [21, 22]. Most large cohort studies report a significant predictive value for radiographic damage on the HAQ DI. The lack of significance in our cohort might possibly be explained by the fact that we only used the Sharp/van der Heijde and
Larsen scores of the foot and ankle, scores of the hands and large joints were not included. In most studies, the Sharp/ van der Heijde score is not specified. Hulsmans et al. demonstrated that approximately half of the Sharp/van der Heijde score could be attributed to the damage of the feet. Extrapolating this to our current data, one might assume that the correlations regarding radiographic damage would have been larger [17]. Moreover, the total number of patients in this study was only small.

Although lately more interest in the foot in RA arises, we still think that the subject is somewhat neglected. It is illustrative that in the DAS 28 , the most widely used instrument to measure disease activity in RA, the feet are not included, sometimes leading to an invalid definition of remission in individuals [23]. This may not only lead to insensitive scoring on population level (in the case of research) but also to the neglect of foot inflammation or damage, especially where we sense a tendency towards more strategy (DAS 28) driven care [24-26]. Within the rheumatic foot, most attention is focussed on the joints of the forefoot. However, our study supports the idea that involvement of the hindfoot and ankle may contribute to impairment and disability in the same way as the forefoot as has been suggested earlier [1, 15].

A limitation of this study is the small number of patients studied, which limits the ability to find strong correlations, but despite the small number and weak correlations, we found some significant correlations indicating the existence of true relationships. Another drawback is that the cross-
Table 3 Regression analysis with HAQ DI as the dependent variable

Standardized coefficients $(b)$ and their CI, adjusted $R^{2} 0.64$ FFI Foot Function Index, US ultrasound, $S v d H$ Sharp/van der Heijde, $C I$ confidence interval

\begin{tabular}{lllll}
\hline & & \multicolumn{2}{l}{$95 \%$ CI of the regression coefficient } \\
\cline { 3 - 4 } Model & Regression coefficients & Lower bound & Upper bound & $p$ value \\
\hline (Constant) & & -0.401 & 0.310 & 0.798 \\
Disease duration & 0.478 & 0.001 & 0.003 & 0.000 \\
FFI 5 total pain score & 0.545 & 0.012 & 0.023 & 0.000 \\
Swelling ankle & 0.281 & 0.140 & 0.521 & 0.001 \\
US synovitis total score & 0.118 & -0.013 & 0.071 & 0.176 \\
SvdH total score & 0.068 & -0.005 & 0.011 & 0.428 \\
\hline
\end{tabular}


sectional design obstructs conclusions regarding time relations. However, cross-sectional studies, including patients with a broad range of disease durations, seem to provide fairly reliable estimates of the course of health outcomes [27]. Future research should focus longitudinally on the relation between clinical signs and structural damage of the foot and especially the ankle.

In conclusion, we suggest that in RA patients, pain and swelling of the ankle contribute more to disability than forefoot signs. In daily clinical practice and clinical research, rheumatologists should pay attention to the ankle and hindfoot as well as they contribute to disability.

\section{Disclosures None}

Open Access This article is distributed under the terms of the Creative Commons Attribution Noncommercial License which permits any noncommercial use, distribution, and reproduction in any medium, provided the original author(s) and source are credited.

\section{References}

1. Michelson J, Easley M, Wigley FM, Hellmann D (1994) Foot and ankle problems in rheumatoid arthritis. Foot Ankle Int 15(11):608-613

2. Budiman-Mak E, Conrad KJ, Roach KE (1991) The Foot Function Index: a measure of foot pain and disability. J Clin Epidemiol 44(6):561-570

3. van der Leeden M, Steultjens M, Dekker JH, Prins AP, Dekker J (2007) The relationship of disease duration to foot function, pain and disability in rheumatoid arthritis patients with foot complaints. Clin Exp Rheumatol 25(2):275-280

4. Kuper HH, van Leeuwen MA, van Riel PL, Prevoo ML, Houtman PM, Lolkema WF et al (1997) Radiographic damage in large joints in early rheumatoid arthritis: relationship with radiographic damage in hands and feet, disease activity, and physical disability. Br J Rheumatol 36(8):855-860

5. Prevoo ML, Van't Hof MA, Kuper HH, van Leeuwen MA, van de Putte LB, van Riel PL (1995) Modified disease activity scores that include twenty-eight-joint counts. Development and validation in a prospective longitudinal study of patients with rheumatoid arthritis. Arthritis Rheum 38(1):44-48

6. Szkudlarek M, Court-Payen M, Jacobsen S, Klarlund M, Thomsen HS, Ostergaard M (2003) Interobserver agreement in ultrasonography of the finger and toe joints in rheumatoid arthritis. Arthritis Rheum 48(4):955-962

7. van der Heijde D (1999) How to read radiographs according to the Sharp/van der Heijde method. J Rheumatol 26(3):743-745

8. Larsen A, Dale K, Eek M (1977) Radiographic evaluation of rheumatoid arthritis and related conditions by standard reference films. Acta Radiol Diagn (Stockh) 18(4):481-491

9. Spiegel TM, Spiegel JS, Paulus HE (1987) The joint alignment and motion scale: a simple measure of joint deformity in patients with rheumatoid arthritis. J Rheumatol 14(5):887-892

10. Boers M, Jacobs JW, van Vliet Vlieland TP, van Riel PL (2007) Consensus Dutch Health Assessment Questionnaire. Ann Rheum Dis 66(1):132-133

11. Riemsma RP, Taal E, Rasker JJ, Houtman PM, Van Paassen HC, Wiegman O (1996) Evaluation of a Dutch version of the AIMS2 for patients with rheumatoid arthritis. Br J Rheumatol 35(8):755-760
12. Kuyvenhoven MM, Gorter KJ, Zuithoff P, Budiman-Mak E, Conrad KJ, Post MW (2002) The foot function index with verbal rating scales (FFI-5pt): a clinimetric evaluation and comparison with the original FFI. J Rheumatol 29(5):10231028

13. Molenaar ET, Voskuyl AE, Dijkmans BA (2002) Functional disability in relation to radiological damage and disease activity in patients with rheumatoid arthritis in remission. J Rheumatol 29 (2):267-270

14. O'Connell PG, Siegel KL, Kepple TM et al (1998) Forefoot deformity, pain, and mobility and rheumatoid and nonarthritic subjects. J Rheumatol 25(9):1681-1686

15. Turner DE, Woodburn J (2008) Characterising the clinical and biomechanical features of severely deformed feet in rheumatoid arthritis. Gait Posture 28(4):574-580

16. Drossaers-Bakker KW, Kroon HM, Zwinderman AH, Breedveld FC, Hazes JM (2000) Radiographic damage of large joints in long-term rheumatoid arthritis and its relation to function. Rheumatology (Oxford) 39(9):998-1003

17. Hulsmans HM, Jacobs JW, van der Heijde DM, van AlbadaKuipers GA, Schenk Y, Bijlsma JW (2000) The course of radiologic damage during the first six years of rheumatoid arthritis. Arthritis Rheum 43(9):1927-1940

18. Plant MJ, O'Sullivan MM, Lewis PA, Camilleri JP, Coles EC, Jessop JD (2005) What factors influence functional ability in patients with rheumatoid arthritis. Do they alter over time? Rheumatology (Oxford) 44(9):1181-1185

19. Belt EA, Kaarela K, Maenpaa H, Kauppi MJ, Lehtinen JT, Lehto MU (2001) Relationship of ankle joint involvement with subtalar destruction in patients with rheumatoid arthritis. A 20-year followup study. Joint Bone Spine 68(2):154-157

20. Welsing PM, Fransen J, van Riel PL (2005) Is the disease course of rheumatoid arthritis becoming milder? Time trends since 1985 in an inception cohort of early rheumatoid arthritis. Arthritis Rheum 52(9):2616-2624

21. Jansen LM, van der Horst-Bruinsma IE, van Schaardenburg D, Bezemer PD, Dijkmans BA (2001) Predictors of radiographic joint damage in patients with early rheumatoid arthritis. Ann Rheum Dis 60(10):924-927

22. Rupp I, Boshuizen HC, Dinant HJ, Jacobi CE, van den Bos GA (2006) Disability and health-related quality of life among patients with rheumatoid arthritis: association with radiographic joint damage, disease activity, pain, and depressive symptoms. Scand J Rheumatol 35(3):175-181

23. Landewe R, van der Heijde D, van der Linden S, Boers M (2006) Twenty-eight-joint counts invalidate the DAS28 remission definition owing to the omission of the lower extremity joints: a comparison with the original DAS remission. Ann Rheum Dis 65 (5):637-641

24. Goekoop-Ruiterman YP, de Vries-Bouwstra JK, Kerstens PJ, Nielen MM, Vos K, van Schaardenburg D et al (2010) DASdriven therapy versus routine care in patients with recent-onset active rheumatoid arthritis. Ann Rheum Dis 69(1):65-69

25. Schipper LG, Kievit W, den Broeder AA et al. (2011) Treatment strategies aiming at remission in early rheumatoid arthritis patients: starting with methotrexate monotherapy is cost-effective. Rheumatology (Oxford). doi:10.1093/rheumatology/ker084

26. Soubrier M, Lukas C, Sibilia J, Fautrel B, Roux F, Gossec L et al (2011) Disease activity score-driven therapy versus routine care in patients with recent-onset active rheumatoid arthritis: data from the GUEPARD trial and ESPOIR cohort. Ann Rheum Dis 70 (4):611-615

27. Rupp I, Boshuizen HC, Roorda LD, Dinant HJ, Jacobi CE, van den Bos G (2006) Course of patient-reported health outcomes in rheumatoid arthritis: comparison of longitudinal and crosssectional approaches. J Rheumatol 33(2):228-233 